\title{
Total aflatoxins load and phytochemical composition of Cola nitida (Kola Nut) samples purchased within Jos metropolis
}

\author{
*Samuel Y. Gazuwa ${ }^{1}$ Kiri H. Jaryum ${ }^{1}$ andAjayi Stephen ${ }^{2}$ \\ ${ }^{I}$ Department of Biochemistry, College of Medical Sciences, University of Jos, PMB 2084, Jos. \\ ${ }^{2} 11$, AkibuBusari Street, Igando, Lagos, Nigeria.
}

\begin{abstract}
The total Aflatoxin load and phytochemicals in Cola nitida (kolanut) were quantified and qualified respectively. Enzyme linked immunosorbent assay (ELISA)-Colorimetric technique and standard qualitative procedure for phytochemical screening were applied. Prior to the quantification of total aflatoxins, samples were extracted using extraction mixture containing methanol and water in ratio 70:30 v/v, aflatoxin conjugate substrate solution, stop solution and aflatoxin standard were used to achieve the setout objectives of this work. Ten samples each of red and cream colour Cola nitida were purchased fresh and divided into two: a portion each of both varieties was sundried whereas others were kept in a damp place to retain moisture. InStat 3 statistical software was used to analyse the data and the student's t-test was chosen to analyse the results obtained. $P$ value of 0.01 was considered significant. The results obtained indicated the dampened samples to be more contaminated with aflatoxins compared to the dried forms albeit relative to the maximum limit of total aflatoxins for both ready to eat food $(4 \mu \mathrm{g} / \mathrm{kg})$ and other foods $(9 \mu \mathrm{g} / \mathrm{kg})$, both types had higher total aflatoxin content $(p<0.01)$. The results were: $13.3 \mu \mathrm{g} / \mathrm{kg}$ for dried red, $16.05 \mu \mathrm{g} / \mathrm{kg}$ for wet red, $10 \mu \mathrm{g} / \mathrm{kg}$ for dried cream and $15.8 \mu \mathrm{g} / \mathrm{kg}$ for wet cream. Red species appeared to have moreaflatoxin both in the damp and dried forms. Phytochemicals such as tannins, cardiac glycosides were present in all the samples. However, dried forms of the samples contained almost all the phytochemicals analysed but the damped forms did not contain resins and terpenes. The damped form of the cream coloured samples did not contain terpenes.
\end{abstract}

Key words: aflatoxins, Cola nitida, ELISA, phytochemicals, and fluorescence.

\section{Introduction}

Plants synthesize a variety of substances in addition to their metabolites, which include the phenolics, terpenes, steroids, alkaloids, glycosides, flavonoids and aflatoxins. Aflatoxins are a family of secondary metabolites produced by toxigenic strains of the ubiquitous food spoilage mould fungi, Aspergilus flavus, Aspergilus parasiticus and to a lesser extent other mould species. They are difuranocoumarin derivatives produced by a polyketide pathway in these organisms. They occur as four parental types aflatoxins $\mathrm{B}_{1}$, $\left(\mathrm{C}_{17} \mathrm{H}_{12} \mathrm{O}_{6}\right), \mathrm{B}_{2}\left(\mathrm{C}_{17} \mathrm{H}_{14} \mathrm{O}_{6}\right), \mathrm{G}_{1},\left(\mathrm{C}_{17} \mathrm{H}_{12} \mathrm{O}_{5}\right)$ and $\mathrm{G}_{2}\left(\mathrm{C}_{17} \mathrm{H}_{14} \mathrm{O}_{7}\right)$.Aflatoxins $\mathrm{M}_{1}$ (4-hydroxyaflatoxin $\left.\mathrm{B}_{1}\right)$ and $\mathrm{M}_{2}$ (4hydroxyaflatoxin $\mathrm{B}_{2}$ ) are metabolites of aflatoxins $\mathrm{B}_{1}$ and $\mathrm{B}_{1}$ respectively. One example of foods that aflatoxins infest is Cola nitida (Kola Nut), which is commonly eaten by people in the tropics including Nigeria. The factors that favour the production of aflatoxins, especially by Aspergilus flavus, include $85 \%$ relative humidity, $9-32 \%$ moisture content of the substrate and high temperature with $25^{\circ} \mathrm{C}$ to $32^{\circ} \mathrm{C}$ favouring the maximum production of aflatoxins.

\subsection{Materials}

\section{Materials And Methods}

Blender, Orbital Shaker, Centrifuge tube, Microwell, weighing Balance, ELISA reader and Colorimeter.

\subsection{Chemicals and Reagents}

Extraction mixture containing methanol and water $(70: 30 \mathrm{v} / \mathrm{v})$, conjugate, substrate, stop solution, deionised $\mathrm{H}_{2} \mathrm{O}$, Acetic Acid, Dragendorf Reagent, 5\% Lead $(\mathrm{Pb})$ Acetate, $10 \%$ Ferric Chloride $\left(\mathrm{FeCl}_{3}\right)$, alcoholic Ferric Chloride, concentrated tetraoxosulphate (vi) acid $\left(\mathrm{H}_{2} \mathrm{SO}_{4}\right)$, Acetic Anhydride, Benedicts Reagent, Distilled $\mathrm{H}_{2} \mathrm{O}$, aflatoxin Standard and assay kit (Romer labs incorporated, Singapore).

2.3 Collection of Samples Ten varieties each of kolanut (cream and red colour) were purchased fresh from terminus market in Jos, Plateau State.

2.4 Assay KitsThe assay kit for the determination of total aflatoxin composed of: 96 non-coated dilution microwells (12 eight-well strips) in a microwell holder (sealed in a foil ponch), 6 vials of $1.5 \mathrm{ml}$ of aflatoxin standard $(0,1.0,2.0,4.0,10.0,20.0 \mathrm{ppb}), 1$ bottle of $25 \mathrm{ml}$ of aflatoxin conjugate, 1 bottle of $15 \mathrm{ml}$ of substrate 
solution and 1 bottle of $15 \mathrm{ml}$ of stop solution. All kit components were kept at room temperature range between $18-30^{\circ} \mathrm{C}$.

\subsection{Protocol for Mycotoxin Determination}

Samples were categorised into two; a portion of both the cream and red coloured kolanut was dried while the other was kept damped to make them humid; they were further divided into four (4) groups: dampened cream, dried cream, dampened red and dried red.

\subsection{Qualitative Determination of Aflatoxins in Cola nitada.}

Thin layer chromatography (TLC) was applied to analyse the native beer samples for the presence of aflatoxins. A stock of Aspergillus flavus (SA 586) mycelium was sub-cultured by allowing the stock to stand naturally for 30 days in a well aerated 1 litre Pyrex beaker. At the end of the period, $2.7 \mathrm{~g}$ of the SA 586 stock of the fungus was weighed using a Mettler balance and kept in a 1 litre Pyrex conical flask. $250 \mathrm{ml}$ of extraction mixture was added onto the stock. Using the Soxhlet assembly, the stock was extracted after prior shaking for 1 hour. Extraction mixture used contained chloroform/methanol in the ratio 97:03v/v respectively [1].

\subsection{Determination of Total Aflatoxin}

Samples were grinded separately using a blender base according to groupings above. The analysis was carried out at the Laboratory of the National Agency for Food and Drug Administration and Control (NAFDAC) Kaduna, Nigeria. $5 \mathrm{~g}$ of the pulverised samples were each subjected to the following procedure: measured sample was kept in jars separately labeled. $25 \mathrm{ml}$ of the extraction mixture was added on to the sample in the jar which was then sealed and shaken vigorously for 5 minutes using orbital shaker at $250 \mathrm{rpm}$. The sample was allowed to stand for 2 minutes before separating the top layer of the extract by decantation for subsequent filtration using Whatman filter paper; the filtrate was further filtered through a filtering syringe containing a $0.22 \mu \mathrm{m}$ nylon disc filter before transferring into clean centrifuge tube. $200 \mu \mathrm{l}$ of conjugate was put into microwells followed by the addition of $100 \mu \mathrm{l}$ of aflatoxin standards thus: $0 \mathrm{mg} / \mathrm{ml}, 0.2 \mathrm{mg} / \mathrm{ml}, 0.4 \mathrm{mg} / \mathrm{ml}$, $0.8 \mathrm{mg} / \mathrm{ml}, 2.0 \mathrm{mg} / \mathrm{ml}$, and $4.0 \mathrm{mg} / \mathrm{ml}$ into the $1^{\text {st }}, 2^{\text {nd }}, 3^{\text {rd }}, 4^{\text {th }}, 5^{\text {th }}$ and $6^{\text {th }}$ microwells respectively. Thereafter, $100 \mu \mathrm{l}$ of the samples of kolanut extract were added into the $7^{\text {th }} 8^{\text {th }}, 9^{\text {th }}$ and $10^{\text {th }}$ microwells and then a standard of $10 \mathrm{ppb}$ was added to the11th microwell. It was well mixed after which $100 \mu l$ was transferred into another coated microwell using a multiple 8 channel pipette. It was incubated for 15 minutes and then discarded and washed 5 times with deionised water before wiping with tissue paper. $100 \mu \mathrm{l}$ of substrate was added to the microwell which turned blue, and was incubated for another 5 minutes before finally adding $100 \mu \mathrm{l}$ of stop solution. The sample was taken to ELISA reader for the analysis

\subsection{Phytochemical Screening}

Phytochemical screening was done using standard qualitative procedure [2] and results are as indicated in table 1.

Table 1: Phytochemical composition of kolanut

\begin{tabular}{lcccc}
\hline & Dried Red & Damped Red & Dried Cream & Damped Cream \\
Terpenes & + & - & + & - \\
Steroids & + & + & + & - \\
Tannins & + & + & + & - \\
Phenols & + & - & + & - \\
Resins & + & + & - & + \\
Cardiac glycosides & + & + & - & + \\
Alkaloids & - & - & - & + \\
Saponins & + & + & & + \\
Flavonoids & + & & & + \\
\hline
\end{tabular}

Key: + = present,

$-=$ absent

Table 2: Results of Thin Layer Chromatography of Cola nitidaspecies samples for Aflatoxins

\begin{tabular}{llc}
\hline Sample & Appearance under UV Light $(340 \mathrm{~nm})$ & Observation \\
\hline Dampened Red Kola nut & Bluish fluorescence & +++++ \\
Dried Red Kola nut & Bluish florescence & +++ \\
Dampened Cream Kola nut & Bluish fluorescence & ++++ \\
Dried Cream Kola nut & Bluish florescence & ++ \\
\hline
\end{tabular}

Key:The addition sign(+) defines a direct proportionality; where theintensity of fluorescence is a function of aflatoxin load at $340 \mathrm{~nm}$. 
Total aflatoxins load and phytochemical composition of Cola nitida (Kola Nut) samples .....

Table 3: Mean Total Aflatoxins content of Cola nitida Samples

\begin{tabular}{lccc}
\hline $\begin{array}{l}\text { Well } \\
\text { (Carrier position) }\end{array}$ & Standard & Absorbance Concentration $(\mu \mathrm{g} / \mathrm{ml})$ & \\
\hline 1 & Standard (1) & 0.03 & $0.21 \pm 0.01$ \\
2 & Standard (2) & 0.29 & $1.40 \pm 0.12$ \\
3 & Standard (3) & 0.26 & $2.02 \pm 0.06$ \\
4 & Standard (4) & 0.19 & $4.03 \pm 0.71$ \\
5 & Standard (5) & 0.12 & $10.07 \pm 1.16$ \\
6 & Standard (6) & 0.07 & $20.01 \pm 0.94$ \\
7 & Dried Red & 0.09 & $12.83 \pm 2.35$ \\
8 & Damped Red & 0.74 & $15.54 \pm 1.02$ \\
9 & Dried Cream & 0.12 & $9.82 \pm 0.84$ \\
10 & Damped Cream & 0.07 & $15.63 \pm 1.14$ \\
\hline
\end{tabular}

Note: Samples were diluted $\times 10$.

\section{Discussion}

Kola nut (Cola nitida) is indigenous to West Africa, most notably Sierra Leone, Liberia, Ivory Coast and Nigeria, and may also be found in Gabon and in the Congo River Basin. The vast majority of African kola nut produced is utilised within the continent, particularly the sub-Saharan region.Traditionally, the African kola nut is used in tropical cultures as a stimulant and a "masticatory," with a small piece chewed before each meal to support digestion, and it is also thought to improve the flavor of anything eaten after it. Its popularity is due to the large amounts of caffeine and other substances that act as botanical stimulants, which may also be, like coffee, mildly addictive.

Results from table 1, show the phytochemical composition of kolanut. Cardiac glycoside was present in all the four categories of kolanut. Dried red kolanut was positive for terpenes, steroid, tannin, phenol, resin, saponin and flavonoid while it was negative for alkaloid. Damped red kolanut was positive for tannin, alkaloid and flavonoid while it was negative for terpene, steroid, phenol, resin and saponin. Dried cream kolanut was positive for terpene, steroid, tannin, phenol and resin while it was negative for alkaloid, saponin and flavonoid. Damped cream kolanut was positive for alkaloid, saponin and flavonoid while it was negative for terpene, steroid, tannin, phenol and resin.Phytochemicals are non-nutritive plant chemicals that have protective or disease preventive properties. They are a class of chemical compounds consisting of a hydroxyl group (-OH) bonded directly to an aromatic hydrocarbon group [3]; [4] found in the natural world, present in vegetative foliage[4].They are non-essential nutrients and therefore are not required for sustaining life.

Glycosides toxicity is determined by the type of aglycone moiety attached [4];[3]. In the case of alkaloids,they exert pharmacological activity particularly on the nervous system affecting the action of chemical neurotransmitters like acetylcholine, epinephrine, nor epinephrine, $\gamma$-aminobutyric acid. Alkaloids interfere or compete with action of serotonin in the brain, they affect the autonomic nervous system which includes the regulation of heartbeat, circulation and breathing [5]. Terpenes could be mono-, di-, tri- or tetraterpenes [6]. Resin is a hydrocarbon secretion of many plants, particularly coniferous trees. It is valued for its chemical properties and associated uses, such as the production of varnishes, adhesives, and food glazing agents [6]. Tannins are a group of compounds present in some plants that react with protein forming insoluble protein copolymers. When applied to the skin, they produce a layer under which healing occurs [7]; [3]; [4]. Condensed tannins are used in medicine to aid the healing of wounds [8]. Hydrolysable tannins are of pharmacological interest because of the antiviral and antitumor activities [8];[9].

Table 2 bears results for the qualitative determination of aflatoxin in samples of the nuts. Samples were first subjected to thin layer chromatographic (TLC) technique before viewing the plates under UV Light at $340 \mathrm{~nm}$. Results indicated bluish fluorescence on the TLC plates for all the samples of kola nuts. This would mean aflatoxins $B$ are present in all the kola nut samples analysed but does not mean aflatoxins $G$ are not present in the nuts. Also, whether they are $\mathrm{B}_{1}$ or $\mathrm{B}_{2}$ types is beyond the scope of this article and would therefore require further analysis of the samples.

Results from table 3 show the mean concentrations of aflatoxins in the samples where a significant magnitude of contamination of all the samples was obtained. The levels were higher than the safe limitsfor aflatoxinsin ready-to-eat food of $4 \mu \mathrm{g} / \mathrm{kg}$, as well as other foods put at $9 \mu \mathrm{g} / \mathrm{kg}$. The presence of aflatoxins in Cola nitidawas achieved by viewing the TLC plates under UV light at 340nm. The bluish fluorescence observed on both the test and the control (aflatoxin stock) TLC plates indicated the presence of aflatoxins B in the samples. Mould fungi and bacteria are the main food spoilage organisms causing extensive deterioration of foodstuffs thereby depositing certain chemicals (eg aflatoxins and others) that are not the normal metabolites of intermediary metabolism. These chemicals remain in foodstuffs even after the microorganism is dead or killed. Most of them are produced as part of the chemical defence system of the organism. Many of these abnormal 
metabolites are highly potent toxins [10]. Aflatoxins are secondary metabolites of Aspergillus flavus credited with organ damage especially the liver and readily form adducts with the DNA through epoxidation, orthodemethylation, reduction, hydration, epoxidation, and hydroxylation. Aflatoxins are a perfect example of potent toxins because they are carcinogenic, mutagenic, teratogenic, and being anticoagulants in animals [10].Consumers of Cola nitidaare at the risks of being exposed to the carcinogenic and mutagenic capacity of aflatoxins as well as the risks of the formation of DNA adducts and life-threatening necrotic effects of aflatoxins B.

Where conditions are right, fungi proliferate into colonies and mycotoxin level becomes high.As a norm, Cola nitidaare normally kept damped to guarantee longevity which ironically favours and enhances the proliferation of mycotoxinsand therefore secondary metabolites such as aflatoxins in the nuts. The reason for the production of mycotoxins is not yet known; they are necessary for neither growth nor the development of the fungi [11]. Mycotoxins weaken the receiving hostand therefore the fungus may use them as a strategy to better the environment for further fungal proliferation. The production of these toxins depends on the surrounding intrinsic and extrinsic environments and the toxins vary greatly in their severity, depending on the organism infected and it susceptibility, metabolism and defense mechanism[12]. Aflatoxins are credited with organ damage especially the liver and are of types: aflatoxins $B_{1}, B_{2}, G_{1}$ and $G_{2}$. They readily form adducts with the DNA through epoxidation, ortho-demethylation, reduction, hydration, epoxidation, and hydroxylation. These toxins constitute threat to humans as they are not easily detoxified or removed from a living system.

[1] reported zearalenone, a toxic compound, to be carried over into native beers; since this compound is also produced by mycotoxins just as aflatoxins, Cola nitida consumers stand the risk of inductionof oestrogenic activity, hyperestrogenic effects,credited to zearalenone, leading to still births in both livestocks and humans. Due to the wide distribution of fungi in the environment, aflatoxins are considered the most important contaminants in foods and feeds. According to the Food and Agriculture organization (FAO), more than $25 \%$ of the world's agricultural production is contaminated with mycotoxins, resulting in economic losses in the agricultural industry [13];[14].Since mycotoxins cannot be completely eradicated, establishing reasonable regulatory limits of these toxins and strict implementation to ensure adherence are imperative thereby protecting the health of the populace.

From the kolanut samples analysed, all the samples were contaminated with aflatoxins with levels of $13.3 \mu \mathrm{g} / \mathrm{kg}, 16.05 \mu \mathrm{g} / \mathrm{kg}, 10.0 \mu \mathrm{g} / \mathrm{kg}$ and $15.8 \mu \mathrm{g} / \mathrm{kg}$ for dried cream, dampened red, dried red and dampened cream respectively. These levels are above the international standard for maximum limit of total aflatoxins in ready to eat food of $4 \mu \mathrm{g} / \mathrm{kg}$, as well as other foods put at $9 \mu \mathrm{g} / \mathrm{kg}$.

From the result, it was also discovered that there was variation in themagnitude of contamination as kolanut samples kept dampened were more contaminated with mycotoxins due to the high activity of fungi at humid or moist places. In Kenya, in the year 2004, a notably severe cases of aflatoxin ingestion which killed about 125 people and nearly 200 treated after eating aflatoxin contaminated food was reported [15]. The deaths were mainly associated with homegrown food that had not been treated with fungicides or poorly dried before storage. Due to food shortages at the time, farmers may have been harvesting food produce earlier than normal to prevent thefts from their fields, andimmature crops are more susceptible to infection to mature ones. Mycotoxin have the potential for both acute and chronic health effects via ingestion, skin contact and inhalation. These toxins can enter the blood stream and in the lymphatic system, they inhibit protein sensitivity to bacterial endotoxin [16].

\section{Conclusion}

In this part of the world, kola nuts are always kept moist to ensure their longevity, freshness, 'nutrientscum taste'. Findings indicated wet form of the samples having higher level of the aflatoxins than the dried. The former is the form of choice for leisure, marital contract, and naming ceremonies. Also, kola nuthas a direct satiety/antihunger effect and therefore its consumption, as alternative to food, is common among the people who may not afford three square meals per day.This exposes the consumers of kola nuts to the carcinogenic, mutagenic and other toxic effects of aflatoxins. This resultant moist condition under which kola nuts are kept favours the growth of mycotoxins which enter the food chain. The toxic effects of aflatoxins represent a severe health risk for consumers and also a risk factor for the economy because contaminated products do not satisfy export requirements.

\section{References}

[1]. Z.S.COkoye, Carryover of aflatoxin $\mathrm{B}_{1}$ in contaminated substrate corn intoNigerian native beer,Bull. Environmental Contaminants and Toxicology,37, 1986, 482-489.

[2]. G.E Trease, and W.C Evans, Textbook of dopamine (Bailliere Tindal, 1986).

[3]. I Podolsk, A. Galanty, and D. Sobolewska, Saponins as cytotoxic agents: a review. Phytochem Rev; 9(3), 2010, 425-474.

[4]. P.JHans,Plant biochemistry $\left(6^{\text {th }}\right.$ ed. Willy -Liss. New York, 2005)

[5]. G.P Kumar, and F. Khanum, F, Neuroprotective potential of phytochemicals. Pharmacogn Rev; 6(12), 2012, 81-90.

[6]. E Oldfield, E and F Lin, Terpene biosynthesis: modulatory rules. Angew Chem Int Ed; 52(5), $2013,1124-1137$. 
[7]. H.A Fozzard, Cellular mechanism of action of cardiac glycosides. J Am Coll Cardiol; 5(5s1), 1985,10A-15A

[8]. L.T. Dabak, Plant taxonomy and origin of traditional medicine201 (72) 21

[9]. M Pandey1, M Debnath,SGupta2, and S.K Chikara2, S.K, Phytomedicine: an ancientapproach turning into future potential source of therapeutics. Journal of Pharmacognosy and Phytotherapy; 3(2), 2011, 27-37.

[10]. Z.S.C Okoye, G.I Adoga, D.K Obatomi, and S.E Agina, Mycotoxin contaminants of Nigerian food crops,(ISBN 978-166 - 069 $1,1992 b)$.

[11]. E.M Fox, and B.J Howlett, Secondary metabolism, regulation and role in fungal biology. Curr.Opin.Microbiol,11(6),2008, $481-497$.

[12]. H.S Hussein, and J.M Brasel, Toxicity, metabolism and impact of mycotoxins on humans and animals. Toxicology167(2), 2001, $101-54$.

[13]. B Kabak, A.D.W Dobson, and I Var, Strategies to prevent mycotoxin contamination of food and animal feed: a review. Critical Reviews in Food Science and Nutrition; 46(8), 2006, 593-619.

[14]. O.M Iheshiuhor, O.K Esonu, A.A Chuwuka, I.C Omede, I.C Okoli, and I.P Ogbuewu, I.P, Effects of mycotoxins in animal nutrition: a review. Asian Journal of Animal Sciences; 5, 2011: 19-33.

[15]. L. Lewis, M. Ousongo, and H. Njapan,Aflatoxin contamination of commercial food products during an outbreak of acute aflatoxicosis in eastern and central Kenya. Environ. Health Perspect. 113(12), 2005, 1763-7.

[16]. G Thad, Indoor environmental quality. (Chelsea, mich: Lewis publishers. ISBN 1-56670-402-2, 2001). 